\title{
Moral distress among Ugandan nurses providing HIV care: A critical ethnography
}

\author{
Jean N. Harrowing ${ }^{\mathrm{a}, *}$, Judy Mill ${ }^{\mathrm{b}}$ \\ ${ }^{\text {a }}$ Faculty of Health Sciences, University of Lethbridge, 4401 University Drive West, Lethbridge, Alberta, Canada T1K 3M4 \\ ${ }^{\mathrm{b}}$ Faculty of Nursing, University of Alberta, Edmonton, Alberta, Canada
}

\section{A R T I C L E I N F O}

\section{Article history:}

Received 16 June 2009

Received in revised form 29 October 2009

Accepted 8 November 2009

\section{Keywords:}

Critical ethnography

HIV/AIDS

Moral distress

Nursing

Uganda

\begin{abstract}
A B S T R A C T
Background: The phenomenon of moral distress among nurses has been described in a variety of high-income countries and practice settings. Defined as the biopsychosocial, cognitive, and behavioural effects experienced by clinicians when their values are compromised by internal or external constraints, it results from the inability to provide the desired care to patients. No research has been reported that addresses moral distress in severely resource-challenged regions such as sub-Saharan Africa.

Aim: To describe the manifestation and impact of moral distress as it was experienced by Ugandan nurses who provided care to HIV-infected or -affected people.

Method: A critical ethnography was conducted with 24 acute care and public health nurses at a large referral centre in Uganda. Data were collected through interviews, observation, and focus group discussions.

Results: Participants described their passion for nursing and commitment to patients. They experienced moral distress when a lack of resources put patients' wellbeing at risk. The trauma imposed by systemic challenges on the nursing profession was acknowledged, as was the perception that the public blamed nurses for poor patient outcomes. However, participants were determined to serve to the best of their abilities and to take satisfaction from any contributions they were able to make. They cited the importance of education in the development of their capacity to provide care with a positive attitude, and demonstrated a collective resilience as they discussed strategies for addressing issues that affected them and their colleagues.

Conclusions: The experience of moral distress among nurses in Uganda differed somewhat from the experience of nurses in high-income countries. Constraints imposed by the inability to implement skills and knowledge to their fullest extent, as well as a lack of resources and infrastructure may result in the omission of care for patients. Moral distress appears to manifest within a relational and contextual environment and participants focussed on the impact for patients, communities, and the nursing profession as a whole, rather than on their own personal suffering. The opportunity for continuing education led to strategies to transform personal attitudes and practice as well as to enhance the presentation of the profession to the public.
\end{abstract}

(c) 2009 Elsevier Ltd. All rights reserved.

\footnotetext{
* Corresponding author. Tel.: +1 403394 3944; fax: +1 4033292668.

E-mail address: harrjn@uleth.ca (J.N. Harrowing).
}

\section{What is already known about the topic?}

- Nurses in high-income countries encounter moral distress in a wide range of practice settings, but little has been reported about the experiences of nurses in low- and middle-income countries. 
- Moral distress manifests as physical, emotional, cognitive, and behavioural symptoms and results from the inability to provide the desired level of care to patients because of internal or external constraints that compromise the nurse's values and beliefs about nursing care.

- The overwhelming burden of HIV illness in Uganda imposes severe constraints on nurses' ability to respond adequately to the needs of patients.

\section{What this paper adds}

- Although Ugandan nurses are haunted by their inability to ease the suffering of HIV-infected and -affected patients and have limited choices about strategies for addressing the problem, they acknowledge the impact of continuing education on their capacity to transform their attitudes and approaches toward the provision of nursing care.

- Ugandan nurses express concern about the public's understanding of their role and performance of nursing care, and worry that members of the profession may lose sight of the essence of nursing in the wake of inadequate resources, negative public perception, and staggering workloads.

- With profound resilience and perseverance, Ugandan nurses demonstrate the importance of the relational and contextual environment in shaping their collective understanding of and response to the experience of moral distress.

Virtually every person in Uganda is affected by HIVeither a family member is infected, ill, or has died of AIDS, or the individual him/herself is infected. Nurses and nursemidwives (hereafter referred to as nurses) are confronted daily by the overwhelming and complex needs of the sick. Constrained by insufficient staffing levels, inadequate organizational policy frameworks, few opportunities for continuing education, and a critical lack of essential supplies such as gloves, medications, and sterile equipment, nurses struggle to provide care that is congruent with their professional and ethical standards. Nurses experience moral distress as a consequence of being unable to attain those standards.

The purpose of this article is to discuss the context and manifestation of moral distress as it emerged during a qualitative study that was conducted with 24 Ugandan nurses to explore the impact of HIV education on their lives. We describe the coping strategies employed by the participants and argue that the phenomenon is shaped and defined by the social, economic, and cultural milieu in which it is experienced.

\section{Background}

There is widespread consensus that moral distress forms a significant part of the fabric of nursing practice. Defined initially by Jameton (1984) as the painful emotions experienced by nurses in situations when they are cognizant of the morally appropriate actions to take but find themselves limited by institutional barriers, the term was subsequently applied to biomedical problems that were "intermittently occurring and dramatic" (Corley, 2002, p. 637). However, Austin et al. (2005) pointed out that the daily practice of nurses abounds with ethical issues that are difficult to define and articulate. Furthermore, internal constraints such as fear or doubt as well as external ones may prevent the chosen action. A range of uncomfortable feelings as well as physical, cognitive, and behavioural symptoms may indicate the presence of moral distress in an affected individual. The Canadian Nurses Association (2008, p. 6) defines moral or ethical distress as situations where:

Nurses know or believe they know the right thing to do, but for various reasons (including fear or circumstances beyond their control) do not or cannot take the right action or prevent a particular harm.

When values and commitments are compromised in this way, nurses' identity and integrity as moral agents are affected and they feel moral distress.

The experience of moral distress has been reported in nurses working in a range of acute, long-term care, and community settings and clinical areas (see Table 1). The sequelae of moral distress include a variety of biopsychosocial effects (Gutierrez, 2005), diminished job satisfaction (Rice et al., 2008), avoidance of the context or setting in which the distress occurred (Hanna, 2005), use of alcohol and drugs (Hanna, 2005), decreased capacity for caring (Nathaniel, 2006), symptoms of burnout and leaving the profession of nursing altogether (Aiken et al., 2002; Meltzer and Huckabay, 2004; Tiedje, 2000). Many of these authors alluded to a connection between moral distress and the challenges associated with nurse retention in the workforce.

Discussion of barriers to good nursing practice in lowand middle-income countries (LMIC) focuses on challenges created by the HIV pandemic. In 2007, 68\% of the world's new infections occurred in sub-Saharan Africa (UNAIDS, 2007) where AIDS continues to be the primary cause of death. On the frontlines of health care delivery, African nurses face many daunting challenges. There is a lack of access to basic supplies, such as gloves and syringes, resulting in exposure to serious health risks (International

Table 1

Examples of 'moral distress' in the nursing literature.

\begin{tabular}{ll}
\hline Author(s) & Clinical setting/population \\
\hline Gutierrez (2005), Meltzer and & Critical care \\
Huckabay (2004), Sundin-Huard & \\
and Fahy (1999) & \\
Aiken et al. (2002), Corley et al. (2005), & Medical/surgical care \\
Rice et al. (2008) & \\
Pijl Zieber et al. (2008) & Long-term care \\
Salmond and Ropis (2005) & Home care \\
Cohen and Erickson (2006) & Oncology \\
Tiedje (2000) & Perinatal care \\
Nathaniel (2006) & Not specified \\
Hanna (2005) & Care of women with \\
& elective abortions \\
\hline
\end{tabular}


Council of Nurses, 2000; Stallknecht, 1998). Other obstacles for health care providers include stigma and discrimination (Holzemer et al., 2007; Mwinituo and Mill, 2006; Okafor and Holder, 2004), inadequate knowledge (Walusimbi and Okonsky, 2004), frustration and stress related to heavy workloads (Mavhandu-Mudzusi et al., 2007; Turan et al., 2008), and negative attitudes (Mbanya et al., 2001). Few authors acknowledge a specific association between such barriers and moral distress, however. As noted by Fournier et al. (2007) and Hanna (2004), the phenomenon has been widely observed and described in North American settings yet little is known about it in the context of other cultures, ethnicities, educational levels, and sociopolitical environments. In particular, there appears to be a complete lack of research reported in the scholarly literature that explores moral distress among nurses in sub-Saharan Africa.

In this paper, we draw on results of a qualitative study conducted in Uganda in 2006-2008 that examined the impact of a 6-month HIV education program on 24 registered nurses. Following completion of the program, study participants were invited to share their professional and personal experiences related to care of people infected or affected by HIV. Briefly, the nurses reported that participation in the program enabled them to address many challenges that interfered with their ability to provide quality care to people with HIV illness. They envisioned new possibilities for themselves as holistic and collaborative caregivers with greater capacity to positively influence service delivery and patient outcomes. They also came to understand the power of education to motivate and prepare themselves for leadership and advocacy roles with respect to policy development and other forms of political action. Full details of the study are provided elsewhere (Harrowing, 2009); in this article we focus on moral distress, which emerged as a dominant theme in the data.

\section{Purpose}

The overall purpose of the study was to address the question: What is the impact of an AIDS education program on the lives of a group of Ugandan nurses and nursemidwives? In addition to gaining greater awareness of the effect of education on the professional practice of nurses, it was deemed important to explore possible sequelae in the personal and social lives of the women. Specific research goals were: (1) to better understand the implications of an educational intervention on various aspects (including professional, personal, and social) of the lives of Ugandan nurses; (2) to identify injustices and power inequities that affect the lives of the nurses and strategies that might be implemented to address these concerns; and (3) to engage the nurses in capacitybuilding innovations that would ultimately enable them to enhance their care of individuals, families, and communities who are affected by HIV and AIDS. The purpose of this article is to discuss the phenomenon of moral distress as it was described and defined by participants as an aspect of their nursing practice and context.

\section{Method}

The research was undertaken using a critical focused ethnographic methodology as outlined by Carspecken (1996). This approach was chosen in order to gain understanding, within a limited duration of time, about how the participants interpreted their experiences and made choices that influenced their behaviours within the context of their lives as nurses in a LMIC. Guided by a belief that science is subtly biased in favour of privileged groups, the critical ethnographer endeavors to disrupt commonly held assumptions and reveal underlying operations of power and control (Cook, 2005; Madison, 2005). We anticipated that opportunities for Ugandan nurses to develop professional knowledge and skills, engage in a full scope of practice activities, and influence HIV policy formulation might be circumscribed by social, political, economic, gender, and cultural factors that would be important to probe and expose in the process of conducting the research. Participants' experiences of being selected for an educational program presented an ideal circumstance in which such factors could be explored.

Three trips were made to Uganda for data collection over a 2-year period, for a total of 18 weeks spent in the country. Data were gathered through individual semistructured interviews with the nurses as well as participant observation during counseling sessions between the nurses and patients, regular duties at the work site, and meetings of the nurses. An interview guide was developed at the outset of the project and revised over time to reflect themes that began to emerge from the data. Interviews lasted 60-100 min and were audiotaped with the consent of the participant; extensive notes were taken during and after the interview for one who preferred not to be taped. Tapes and field notes were transcribed and entered into a qualitative data management software program (NVivo7); thematic coding occurred simultaneously with data collection. The first author also sought opportunities to engage in and learn about community activities (such as attending cultural events and church services, traveling on public transportation, taking lessons in the local language, reading local newspapers and magazines, and sharing meals in private homes). Iterative verification strategies to ensure rigor, including frequent consultation and debriefing with experienced qualitative researchers, maintenance of detailed field notes and memos, prolonged engagement and persistent observation, and the concurrent collection and analysis of data (Morse et al., 2002), were incorporated throughout the research process.

\subsection{Ethics}

Approval for the study was acquired from the relevant academic and health care institutions in the first author's home country and in Uganda. Informed consent was obtained upon initial contact with the participants and reconfirmed with each subsequent encounter. Participants' patients granted permission for the first author to attend counseling sessions after the purpose of her presence was explained to them and their questions and concerns addressed. 


\subsection{Participants}

The senior nursing administrator for the hospital selected 25 registered nurse employees for the educational program; 24 of them consented to participate in the study. All were female and represented a broad cross-section of nursing practice, including most areas of acute care as well as community health. Many were dually trained as midwives, and all had 15-35 years of nursing experience. A number were in management or supervisory positions and were within 10 years of retirement (mandatory at age 60 ). All held diplomas in nursing, two had baccalaureate degrees, and one was working on a master's degree. Each participant was interviewed at least once; one or two follow-up interviews were held with 14 participants to further clarify or expand on the information and ideas presented at the first meeting. Fourteen were observed in their worksites and/or in counselling sessions with patients, for a total of $100 \mathrm{~h}$ of observation.

\section{Findings}

Participants shared numerous observations about the many factors that shaped the trajectory of their nursing practice over the years of their careers. It was interesting to see the shifts that occurred over 2 years of data collection in their attitudes and interpretations about power and responsibility with regard to choices and actions. Early conversations were replete with examples of frustration and hopelessness at participants' perceived inability to initiate change in the system. Two years later, during the first author's final trip to Uganda, there was a much stronger sense of optimism and hopefulness, blended with a pragmatism grounded in a realistic awareness that change would come slowly, if at all. Participants discussed the idealistic foundations of their choices to become nurses, the slow erosion of their hopes for themselves and the profession as a whole as forces conspired to erect overwhelming barriers to care. Eventually there was the growing realization that their encounter with education could inspire new awareness of their abilities and power to evoke change.

\subsection{Called to serve}

The participants framed their experiences within the context of the meaning of nursing practice and its importance in their lives. To them, nursing was a passion and a way of being in the world. They identified themselves as nurses in all aspects of their lives, sharing their knowledge and skill with family, friends, and communities. Many stated that they were "called by God to serve" and were responding to a deep need to care for people and alleviate suffering. Some recalled positive encounters with nurses as a result of childhood illness or injury that affected their decision to join the profession. Others aspired to the status and prestige conferred on nurses in their villages. As a child, Sandra ${ }^{1}$ had observed that nurses

\footnotetext{
${ }^{1}$ Participants chose or were assigned a pseudonym.
}

in her community were consulted and "involved in every aspect of life," a powerful role not normally enjoyed by women, and she intended to earn such respect for herself by emulating her older sisters and becoming a nurse. For those whose families were unable to pay university tuition fees, nursing was a more affordable option. Regardless of the reason for their choices, participants were committed members of the nursing profession and were proud of their many years of service. In contrast, the participants commented on their perspectives of the characteristics and motivations of contemporary nursing students, noting that for some, nursing was not their first choice of careers, but a default based on secondary school grades. Those students who failed to meet the entrance requirements of medical or law schools were offered seats in the 2-year nursing diploma program, and thus did not always display the passion for nursing that the study participants themselves felt.

The participants had seen many changes in health care and nursing over their years of nursing practice. Unlike that of the early days of their careers, the existing environment was notable for its lack of adequate funding, staff, supplies and equipment. Participants cited as examples the lack of linen for the beds, food, medications, gloves and other protective gear. Patients were asked to bring or acquire most of these items; when they could not afford them, they did without. It was not uncommon for the nurses to purchase, from their own personal resources, medications or food for the patients. Nursing units with 25 beds often admitted $80-100$ patients and were staffed by one or two nurses. The demand for services greatly exceeded the available resources; consequently the nurses were unable to offer the quality of care they wished to provide.

The participants recognized that HIV illness and its associated costs related to prevention, treatment, and care interventions placed a huge burden on the health care system. They acknowledged the social and political factors that created the situation, and felt that they had a responsibility to compensate for deficiencies in health care delivery. It was "not an option to leave the patient to die," according to Sandra, despite the limitations on the nurses' capacity to provide adequate services. In their assumption of this responsibility, the nurses experienced a set of powerful emotions that caused them to examine closely their understanding of and commitment to the profession. Consequently, they had to choose a response to the situation that would enable them to carry on functioning in their daily lives.

\subsection{Hurting and haunting}

"Suffering" was the term used by almost all of the participants to describe the universal experience of being unable to provide the quality of nursing care they believed their patients deserved. They acknowledged that the patients suffered, as did they themselves. Sadie witnessed and shared in the distress experienced by a colleague in the intensive care unit who, while working alone, received two critically ill patients. Forced to choose which one he would attend to, he could only watch in despair as the other one 
died. Ruth noted that when a nurse cannot provide for a patient's basic needs, "she gets hurt" and feels she has "done nothing." She recalled on one occasion feeling that she should give up nursing when she checked on a particular patient, only to find that he was dead. She perceived her lack of awareness of his deterioration as negligence and believed that it contributed to the man's death.

Participants described the sense of inadequacy and helplessness that resulted from their inability to provide an acceptable level of care to their patients. Paula was "haunted" by persistent thoughts of the people she could not assist. Ruth observed that failing to meet the patient's needs would result in retribution from two sources: "[the patient] accusing you, the conscience is accusing you." Christine recalled how she "used to feel so bad... When I left duty I still felt that maybe [if I had] remained behind, that patient [might not have] died." Lorna recounted that frequently at the end of the day:

you start reflecting back what you have done through the day and you see somewhere you haven't given and you feel bad. . . [you] didn't really listen to... give what this person was... asking and instead of answering the proper thing - you do something else. So tired, too much work, not enough nurses!

Most participants agreed that they were extremely frustrated by the obstacles and limitations they faced. They described the sense of hopelessness that permeated their practice prior to the education program. Ruth identified a terrible sense of loss in response to the knowledge that the lives of patients and their families were profoundly, and sometimes negatively, affected by her actions. She recognized that her nursing care had changed over the years and her satisfaction with its quality had declined; she experienced significant guilt as a result. Christine observed that "we are not doing as much nursing as we used to do" as a consequence of the lack of resources.

\subsection{Losing the essence}

Participants noted the impact of systemic challenges on the image and functioning of the nursing profession overall. Leanne declared that "nurses in Uganda are traumatized" by the efforts required to deliver quality care. Eunice believed that not only was burnout a risk for individual nurses, but that the profession itself was "crippled" by the constraints that interfered with a positive public perception of nurses' work.

Participants spoke at length about the general public's poor understanding of the role of nurses and the challenges they faced. They perceived that they were unfairly blamed for the poor quality of services delivered under circumstances beyond their control. Most participants observed that the public's interpretation of nurses' behaviours failed to acknowledge the difficult constraints under which they worked. Because nurses worked on the front lines and had continuous contact with patients, they tended to receive the blame for unfortunate outcomes. Yet nurses were seldom in a position to defend themselves, nor did their leaders attempt to raise awareness among the population.
This situation resulted in significant distress for the participants. They desired the public to understand that they were nurses because, as Ruth put it, "I loved to do the work. . I had compassion and a sense in my heart towards people." Their commitment to their patients and profession remained strong, and they struggled to address the need to raise awareness in the general population.

Lorna suggested that nurses were caught in a vicious cycle: the lack of resources led to fatigue and despair, which in turn contributed to a growing negative attitude toward their work and their patients. Nurses then became less conscientious about meeting professional standards, and often failed to appear at the workplace for their scheduled shifts, thus aggravating an already critical situation. Jackie agreed, noting that as nurses' exhaustion intensified and stamina declined, the prevailing attitude might change to a "Who cares?" approach. Eunice concurred: "When you get used to doing things substandard it can become a habit I think. You then lose the essence of doing it fully right."

\subsection{Counting for something}

Despite the emotional toll of chronic inability to meet personal and professional practice standards, participants focused on their good intentions and the contributions they were able to make. Perseverance was a common theme. Jackie quietly declared: "I have been called to serve, and I will serve. It's not that we don't want to do it, but the situation is a-b-c-d. And so we go on like that, day in and day out." Sandra acknowledged the challenges, but was not prepared to admit defeat: "It is a difficult situation but I don't think that we should give up... There's nobody who is going to have it easier than me." The nurses made judicious use of the supplies and equipment to which they had access, and at times performed care even when it put their own health at risk, according to Ruth: "They do their work but they can also be sick-I mean they can also be affected if they don't have the [protective equipment]... But you find they are trying." Christine agreed: "I've learned to make the best use of what I have."

The participants gained satisfaction from any successes, no matter how small. Ruth asserted that: "Even if out of 100 ... you save maybe three or four. That counts for something." There was great satisfaction in maintaining contact with patients whom the participants had counseled during the practicum components of the education program, as they were able to see firsthand the improvement in the patients' health and wellbeing that resulted from the nurses' interventions. A number of participants noted that they achieved a degree of comfort by praying for their patients, particularly those for whom they could do little. In this way, they believed that they were able to contribute something to everyone. Jackie summed up the nurses' approach when she said "You do your best and you leave the Lord to do the rest."

Funding realities were accepted, and choices debated and eliminated: "You are told the government cannot afford to give you what you really want. Should you walk away from those patients in the halls?" Sandra affirmed that this was not a viable choice. Instead she promoted 
engagement in political action by nurses to raise awareness of the critical situation ("You have to make your voice loud"), while striving to provide the best possible care in the meantime. She and her colleagues were convinced that "the way forward remains... education." Participants as a group identified the need to make available to their colleagues similar opportunities for education and engaged in negotiations with hospital administration to implement their ideas. They believed that it was only through professional development activities for nurses and awareness raising campaigns for the public and the decision-makers that improvements would be made. Furthermore, they began to see a role for themselves in bringing about those changes.

The participants perceived the need to choose effective strategies for coping with the suffering they had to endure as a result of providing sub-standard services. None felt that terminating their employment was a viable option, as the chances of finding other employment were minimal at best and all participants depended heavily on the income to support family and extended family members. Sandra spoke for all when she said "I wouldn't think of [giving up]." Ruth noted that if you did what you could do under the circumstances, then "you feel contented." Christine concurred, saying that "sometimes I also fail, but I say I did the best, I did what I could do. I can do nothing more. . . so I'm not going to cry over that." Eunice shared her strategy of "closing the door" and delegating work to other staff when she was overwhelmed and needed time to recover. Lorna suggested that nurses must choose their attitude in order to successfully deal with the dilemmas they experienced. Likewise, Jackie was determined to "move on with the right attitude" and believed that "you really do so through a lot of strength, physical and psychological strength." Using this strategy, she found she was able to sleep well at night.

\section{Discussion}

The narratives of suffering, loss, pain, and trauma paint a compelling picture of the profound complexities and layers of moral distress in the biographies of the participants. It was a cumulative experience that permeated all aspects of the nurses' lives as well as their attitudes toward and ability to provide care for their patients. In her comprehensive review of the literature on moral distress among clinicians, Hanna (2004) noted four themes: conflict associated with early insights; truth telling; anguish or interior suffering; and role morality. The first theme was associated with the distress that resulted from involvement in treatments considered, in the clinical judgment of expert nurses, to be futile (such as trying to keep very young and low-birthweight babies alive in an intensive care setting, for example). This type of issue did not concern the participants in this study; in a resource-challenged environment, the use of complex technology to maintain vital functions was generally not a treatment option.

The second theme concerned the withholding of truth, perhaps news of a grim prognosis, from patients. Interestingly, participants expressed no issues about their previous professional approach to information-sharing with patients. Their role as nurses was to reiterate the pronouncement of the physician and not to offer their interpretation of the diagnosis or prognosis. However, upon completion of the education program, many participants found themselves communicating much more openly and honestly with patients and family members around sensitive topics such as terminal illness and the consequences of certain sexual activities. The participants felt more comfortable discussing the implications and facilitating the patient's problem-solving process, providing explanation where necessary. From an ethical standpoint, they felt that it was their responsibility to provide information to patients that would allow thoughtful decision making. Rather than experiencing distress as a result of truth-withholding, the participants shared a sense of freedom upon learning strategies for approaching difficult topics in a therapeutic manner.

Participants related many examples of anguish and suffering as they described the impact of their inability to provide the care they so wanted to give. This inability was largely related to inadequate resources coupled with overwhelming demand. The suffering was long-standing and manifested as physical, spiritual, and psychological symptoms, congruent with the findings of other authors who have explored this phenomenon (Fournier et al., 2007; McCarthy and Deady, 2008; Pijl Zieber et al., 2008). Most of the participants had practiced nursing long enough that they remembered the pre-HIV days when the demands on the health care system were much less overwhelming and resources were relatively more available. Although suffering was clearly described as a consequence of the participants' inability to enact nursing care as they wished to, it was not the focus of their experience. Rather, discussions about distress emphasized negative public perception of nurses and their roles, and the desire to replace such perception with more positive understandings of the profession along with insight into the issues that resulted in the level of service available to patients. This view of the situation indicates the importance of the collective over the individual in the minds of participants; the notion that what damages one nurse has far-reaching implications for the profession as a whole.

Role morality refers to the strategies used by nurses to accomplish the goals of nursing and speaks to the possibility of disconnecting personal from professional self (Hanna, 2004). Numerous authors (e.g., Cignacco, 2002; Doka et al., 1994) have described the suppressed moral distress and emotional blunting that occurs when nurses execute professional duties that contradict their beliefs about ethical nursing practice. Austin et al. (2005, p. 34) noted that the difficulty is not deciding the right thing to do; the nurse's "greatest difficulty occurs when the choice for the good is quite clear, but implementation of the morally acceptable action is thwarted. The chosen action may be prevented by internal constraints or external ones." Similarly, Pendry (2007) observed that definitions that focus on external constraints fail to acknowledge constraints associated with the nurses' belief system. In this study, there was clear indication that personal was professional, that environmental influences on the quality of nursing care in the institution extended to 
the personal lives of participants. However, in the community, participants saw themselves at greater liberty to offer care without the constraints associated with the workplace. They took great satisfaction from counseling neighbours, raising awareness during encounters in the markets and taxis, and volunteering their services in churches and schools. The nurses' offering of self, knowledge, and skills offset the lack of material resources. The positive response from the recipients of such services alleviated some of the suffering and permitted participants to enjoy some measure of fulfillment from their work. Thus, the creative application of new knowledge and skills permitted the participants to practice according to meaningful values, thereby enabling them to maintain personal and professional integrity despite the challenges inherent in the environment.

Criticism has been aimed at the discourse about moral distress by Paley (2004) who argued that focusing on nurses implies that no other occupational groups are likely to suffer, and that nurses are inherently powerless to reverse the process and effects of moral distress. Likewise, Aita (2006) challenged researchers to seek cases of nurses who have experienced moral distress and who have dealt with it in a positive manner. The focus in much of the literature on factors that thwart nurses' preferred actions fails to account for those factors that protect the moral integrity of the nurses and mitigate the effects of distress-causing obstacles. Some authors discussed burnout and other consequences of moral distress as if they result from the nurse's failure to have the personal resilience necessary for work-related demands (Rodney et al., 2004). Indeed, the participants in this study experienced profound and fundamental challenges that might be expected to result in moral paralysis, yet many elements of a remarkable resilience and perseverance of the participants were observed. Varcoe et al. (2003) suggested that rather than focussing on the individual, we need to view moral distress within the context of a network of individuals acting in relation to one another. Such a framework contributes to our understanding of the impact of constraints on the relationship between nurse and patient, rather than on the nurse's personal experience of suffering. The acute awareness of the "crippling" effects of public perception on the morale and agency of the nursing profession supports a relational approach to the consideration of moral distress.

Although their distress cannot be downplayed or denied, participants' commitment to patients, families, and communities demonstrated that there may be strategies that would allow nurses to overcome the debilitating effects of environmental constraints on their practice. Financial necessity dictated that Ugandan nurses maintain employment at almost any cost; however, it was noteworthy that study participants articulated their ability to select their attitudes in response to the conditions under which they worked. Their experience and qualifications meant that they could have secured work in other countries, yet they indicated little interest in leaving family members behind (a phenomenon that may be partly related to the age of participants; all were nearing the end of their careers and were chosen for the education program based on the assumption that they would be less likely to leave the country in search of international employment). Virtually all participants indicated the importance of service in their understanding of their roles as nurses-service that included off-duty care to neighbours and extended family. Their informal contributions in the community helped to compensate for the frustrations encountered in the institution.

Varcoe et al. (2003, p. 966) discussed nurses' passive acceptance of resource shortages and the "ideology of scarcity," as did the participants in this study. However, completion of the education program and expansion of their own practice enabled the nurses to begin considering other avenues for achieving their goals. They realized that although they might have little direct impact on the availability of supplies and equipment, improved access to education offered another route to making positive changes in their ability to provide good care. Development of a trusting relationship with patients began to take on more importance, and implementation of their new skills provided dramatic and immediate feedback about their ability to provide care using the resources at their disposal. This was a powerful discovery for participants and altered their thoughts about the potential to activate change. They began to discuss strategies for collective approaches to addressing the issues facing them. They rapidly decided that creation of a critical mass of advocates and activists would offer an outlet for frustrations if, as a group, they and their colleagues could identify and address issues of concern to all. Participants recognized that the process would not effect immediate change, but that over time and with continuous effort, a positive impact might be felt.

The findings from this study are limited by the fact that the interpretation of 24 relatively homogenous voices cannot be expected to be applicable to all nurses and nurse-midwives in Uganda. Furthermore, the assumptions that guided the senior administrator's selection of participants for the education program may have affected the research process. In addition, perspectives were not obtained from the participants' co-workers and patients; such data would likely provide a more comprehensive picture of the phenomenon. Future research needs to address the complexity of factors that contribute to and alleviate the experience of moral distress among nurses in LMIC, particularly in view of the fact that the original intent of this study did not focus on that phenomenon.

\section{Conclusion}

Moral distress among nurses is a phenomenon that has received increasing attention in the past decade. It is often associated with nurse recruitment and retention issues as well as general health concerns for this group of health care providers, and thus is of critical interest to the profession. Although much of the discussion emanates from high-income countries, it is apparent that nurses in LMIC also experience moral distress, albeit in a slightly different way. Whereas nurses in high-income countries tend to anguish over the commission of procedures (for example, prolongation of life-extending therapies beyond what nurses feel is reasonable or contributing to quality of life), nurses in Uganda suffered from the omission of care because of a lack of resources such that basic care often 
cannot be provided. Furthermore, nurses may differ in their access to options for addressing moral distress. In LMIC, financial imperative and limited employment opportunities offered few choices to health care providers who wished to avoid or escape negative situations. Instead, such workers benefited from choosing attitudes and responses to circumstances that they found difficult to tolerate in order to maintain integrity and the ability to function appropriately.

It is important to note that moral distress affects more than just the individual who faces a discrete and isolated ethical dilemma. Rather, it manifests within a relational and contextual environment comprising complex structural and interpersonal conditions. Although participants in this study expressed their personal experiences of suffering, the emphasis was always on the impact on patients, communities, and the nursing profession as a whole. As the nurses implemented and refined their new skills, their initial awareness of the inertia associated with large institutions and the sociopolitical milieu in which they were situated was replaced with exploration of strategies to initiate change. They began to see themselves as capable of initiating change through collective effort and constructive resistance to the status quo. Their education became a catalyst for transformation of not only their own attitudes and practices, but also for the presentation of the profession to the public. Future research must focus on investigation of elements of practice and setting that support nurses in their efforts to enact their collective professional values. By fostering a moral community for nursing practice, nurses will enhance not only their capacity for autonomous and ethical practice, but also for the creation of an environment in which the essence of nursing is regained and sustained to the benefit of patients and communities.

\section{Acknowledgements}

Many thanks are due the nurses and nurse-midwives of Uganda for their gracious participation in this research. The authors are grateful to Dr. J. Kulig, Dr. J. Spiers, and Dr. $W$. Kipp for their helpful comments on earlier drafts of this manuscript.

\section{Conflict of interest}

None declared.

\section{Funding}

First author was supported in her doctoral work by the Canadian Institutes of Health Research, Killam Trusts, Faculty of Nursing, University of Alberta, Alberta Registered Nurses Educational Trust, Canadian Nurses Foundation.

\section{Ethical approval}

This study had been approved by University of Alberta, Makerere University, Mulago Hospital.

\section{References}

Aiken, L.H., Clarke, S.P., Sloane, D.M., Sochalski, J., Silber, J.H., 2002. Hospital nurse staffing and patient mortality, nurse burnout, and job dissatisfaction. JAMA 288 (16), 1987-1993.
Aita, V., 2006. Commentary [Nathaniel, A.K. (2006). Moral reckoning in nursing. Western Journal of Nursing Research 28 (4), 419-438]. Western Journal of Nursing Research 28 (4), 439-441.

Austin, W., Lemermeyer, G., Goldberg, L., Bergum, V., Johnson, M.S., 2005. Moral distress in healthcare practice: the situation of nurses. HEC Forum 17 (1), 33-48.

Canadian Nurses Association, 2008. Code of Ethics For Registered Nurses, Ottawa, ON.

Carspecken, P.F., 1996. Critical Ethnography in Educational Research: A Theoretical and Practical Guide. Routledge, New York.

Cignacco, E., 2002. Between professional duty and ethical confusion: midwives and selective termination of pregnancy. Nursing Ethics 9 (2), 179-191.

Cohen, J.S., Erickson, J.M., 2006. Ethical dilemmas and moral distress in oncology nursing practice. Clinical Journal of Oncology Nursing 10 (6), 775-780.

Cook, K.E., 2005. Using critical ethnography to explore issues in health promotion. Qualitative Health Research 15 (1), 129-138.

Corley, M.C., 2002. Nurse moral distress: a proposed theory and research agenda. Nursing Ethics 9 (6), 636-650.

Corley, M.C., Minick, P., Elswick, R.K., Jacobs, M., 2005. Nurse moral distress and ethical work environment. Nursing Ethics 12 (4), 381 390.

Doka, K., Rushton, C.H., Thorstenson, T.A., 1994. Caregiver distress: if it is so ethical, why does it feel so bad? AACN Clinical Issues in Critical Care Nursing 5 (3), 346-352.

Fournier, B., Kipp, W., Mill, J., Walusimbi, M., 2007. Nursing care of AIDS patients in Uganda. Journal of Transcultural Nursing 18 (3), 257-264.

Gutierrez, K.M., 2005. Critical care nurses' perceptions of and responses to moral distress. Dimensions of Critical Care Nursing 24 (5), 229-241.

Hanna, D.R., 2005. The lived experience of moral distress: nurses who assisted with elective abortions. Research and Theory for Nursing Practice 19 (1), 95-124.

Hanna, D.R., 2004. Moral distress: the state of the science. Research \& Theory for Nursing Practice 18 (1), 73-93.

Harrowing, J.N., 2009. The impact of HIV education on the lives of Ugandan nurses and nurse-midwives. Advances in Nursing Science 32 (2), E94-E108.

Holzemer, W.L., Uys, L.R., Makoae, L.N., Stewart, A., Phetlhu, R., Dlamini, P.S., Greeff, M., Kohi, T., Chirwa, M.L., Cuca, Y., Naidoo, J.R., 2007. A conceptual model of HIV/AIDS stigma from five African countries. Journal of Advanced Nursing 58 (6), 541-551.

International Council of Nurses, 2000. Reducing the impact of HIV/AIDS on nursing and midwifery personnel, Geneva, Switzerland, pp. 1-30.

Jameton, A., 1984. Nursing Practice: The Ethical Issues. Prentice Hall, Englewood Cliffs, NJ.

Madison, D.S., 2005. Critical Ethnography: Method, Ethics, and Performance. Sage, Thousand Oaks, CA.

Mavhandu-Mudzusi, A.H., Netshandama, V.O., Davhana-Maselesele, M. 2007. Nurses' experiences of delivering voluntary counseling and testing services for people with HIV/AIDS in the Vhembe District, Limpopo Province, South Africa. Nursing and Health Sciences 9 (4), 254-262.

Mbanya, D.N., Zebaze, R., Kengne, A.P., Minkoulou, E.M., Awah, P., Beure, 2001. Knowledge, attitudes and practices of nursing staff in a rural hospital of Cameroon: how much does the health care provider know about the human immunodeficiency virus/acquired immune deficiency syndrome? International Nursing Review 48 (4), 241-249.

McCarthy, J., Deady, R., 2008. Moral distress reconsidered. Nursing Ethics 15 (2), 254-262

Meltzer, L.S., Huckabay, L.M., 2004. Critical care nurses' perceptions of futile care and its effect on burnout. American Journal of Critical Care 13 (3), 202-208

Morse, J.M., Barrett, M., Mayan, M., Olson, K., Spiers, J., 2002. Verification strategies for establishing reliability and validity in qualitative research. International Journal of Qualitative Methods 1 (2) Article 2http://www.ualberta.ca/ iiqm/backissues/1_2Final/html/morse.html.

Mwinituo, P.P., Mill, J.E., 2006. Stigma associated with Ghanaian caregivers of AIDS patients. Western Journal of Nursing Research 28 (4) 369-382.

Nathaniel, A.K., 2006. Moral reckoning in nursing. Western Journal of Nursing Research 28 (4), 419-438.

Okafor, C.B., Holder, B., 2004. HIV/AIDS related stigma in sub-Saharan Africa: context and consequences. International Journal of Global Health 3 (1), 20-34

Paley, J., 2004. Commentary: the discourse of moral suffering. Journal of Advanced Nursing 47 (4), 364-365.

Pendry, P.S., 2007. Moral distress: recognizing it to retain nurses. Nursing Economic\$ 25 (4), 217-221. 
Pijl Zieber, E., Hagen, B., Armstrong-Esther, C., Hall, B., Akins, L., Stingl, M., 2008. Moral distress: an emerging problem for nurses in long-term care? Quality in Ageing 9 (2), 39-48.

Rice, E.M., Rady, M.Y., Hamrick, A., Verheijde, J.L., Pendergast, D.K., 2008. Determinants of moral distress in medical and surgical nurses at an adult acute tertiary care hospital. Journal of Nursing Management 16 (3), 360-373.

Rodney, P., Brown, H., Liaschenko, J., 2004. Moral agency: relational connections and trust. In: Storch, J.L., Rodney, P., Starzomski, R. (Eds.), Toward a Moral Horizon: Nursing Ethics For Leadership and Practice. Pearson Prentice Hall, Toronto, ON, pp. 154-180.

Salmond, S., Ropis, P.E., 2005. Job stress and general well-being: a comparative study of medical-surgical and home care nurses. Medsurg Nursing 14 (5), 301-309.

Stallknecht, K., 1998. Nurses are the key to effective HIV/AIDS prevention and care. International Nursing Review 45 (6), 173-174.
Sundin-Huard, D., Fahy, K., 1999. Moral distress, advocacy and burnout: theorising the relationships. International Journal of Nursing Practice $5(1), 8-13$.

Tiedje, L.B., 2000. Moral distress in perinatal nursing. Journal of Perinatal \& Neonatal Nursing $14(2), 36-43$.

Turan, J.M., Bukusi, E.A., Cohen, C.R., Sande, J., Miller, S., 2008. Effects of HIV/AIDS on maternity care providers in Kenya. Journal of Obstetric, Gynecologic, \& Neonatal Nursing 37 (5), 588-595.

UNAIDS, 2007. AIDS Epidemic Update: 2007. Geneva, Switzerland.

Varcoe, C., Rodney, P., McCormick, J., 2003. Health care relationships in context: an analysis of three ethnographies. Qualitative Health Research 13 (7), 957-973.

Walusimbi, M., Okonsky, J.G., 2004. Knowledge and attitude of nurses caring for patients with HIV/AIDS in Uganda. Applied Nursing Research 17 (2), 92-99. 